\title{
Torus Palatinus and Torus Mandibularis in a Thai population
}

\author{
Wandee Apinhasmit, ${ }^{a}$, Aree J ainkittivong ${ }^{b}$ and Sompom Swasdisonc \\ a Department of Anatomy, Fa culty of Dentistry, Chula longkom University, \\ Bangkok 10330, Tha iland. \\ b Department of Oral Medic ine, Fa culty of Dentistry, Chula longkom University, \\ Bangkok 10330, Thailand. \\ c Department of Oral Pathology, Faculty of Dentistry, Chula longkom University, \\ Bangkok 10330, Tha iland. \\ * Corresponding author, e-mail: awandee@chula.ac.th
}

Received 24 May 2001

Accepted 6 Nov 2001

\begin{abstract}
The aims of this study were to determine the prevalence, size, shape, and location of torus palatinus (TP) and torus mandibularis (TM), and to investigate their sex- and age-related differences in a Thai population. One thousand two hundred subjects were examined for the presence of both tori at the Faculty of Dentistry, Chulalongkorn University. The prevalence for TP and TM in the subjects was $58.1 \%$ and $31.9 \%$, respectively. TP were significantly more common in females than in males $(67.3 \%$ versus $48.8 \% ; p \varangle 0.001$ ). TP were frequently found in small and medium sizes, spindle-shaped and often located at the combined premolar to molar and molar areas. The prevalence of TM was higher in males than in females ( $34.8 \%$ versus $29.0 \% ; p=0.030$ ). TM occurred most commonly in small size, bilateral multiple form, and was often located at the canine to premolar area. There was a significant correlation between the prevalence of both tori and age ( $p \varangle 0.001$ for TP and $p=0.004$ for TM). The prevalence of both tori in this Thai population were comparable to the Mongoloids and other Asian populations. Statistically significant differences in the prevalence and size of tori in regard to sex and age were also found.
\end{abstract}

KEYWORDS: torus mandibularis; torus palatinus; prevalence.

\section{INTRODUCTION}

The most remarkable exostoses of the human jaws are torus palatinus (TP) and torus mandibularis (TM). TP is a sessile nodule of bone that occurs along the midline of the hard palate. TM is a bony protuberance located on the lingual aspect of the mandible, commonly at the canine and premolar areas. ${ }^{1}$ Although tori ar enot pathologically significant, they may obscure radiographic details of maxillary sinuses and lower premolars. They may al so interfere with the construction and function of removable dentures, as well as oral functional movement. ${ }^{2}$ The prevalence of tori varies widely in different populations, ranging from $0.4 \%$ to $66.5 \%$ for TP $3-17$ and $0.5 \%$ to $63.4 \%$ for TM. $3,6-7,9-12,15-17$ Racial differences appear significant, with a high prevalence in Asian and Eskimo populations. 5, 9-11, 15, 18 Differences in the preval ence of tori between genders have also been reported. Most authors reported TP was more frequent in females, ${ }^{4-8,1} 12,14-16$ while TM affected more males than females., 11-12, 15-16, 19

Theetiology of tori has been investigated, however, no consensus has been found. The postulated causes include genetic factors, ${ }^{11,18,20}$ environmental factors, ${ }^{8,}$ 12, 19, 21 masticatory hyperfunction ${ }^{11-12,15,22}$ and continuous growth. ${ }^{23}$ Recently, the etiology of tori has been postulated to be an interplay of multifactorial genetic and environmental factors. ${ }^{1-2,12-13}$

The present study was performed to determine the prevalence, size, shape and location of the tori and to investigate the sex- and age-related changes of TP and TM in a Thai population.

\section{Materials and Methods}

Our subjects consisted of 1,200 Thais, including dental patients, staff and dental students of the Faculty of Dentistry, Chulalongkorn University. In order to give equal weight to all age and sex groups, 100 cases for each category were randomly selected from the accumulated data. The subjects were divided into six age groups: 13-19, 20-29, 30-39, $40-49,50-59$ and 60 years and over. The mean ages for males and females were $40.2 \pm 17.5$ years and $39.8 \pm 17.3$ years, respectively.

The presence or absence of tori was assessed by clinical inspection and palpation performed by one 
examiner (AJ). Questionable tori were recorded as not present. In cases of positive finding, impressions of the maxillary and the mandibular arches were taken by using al ginate impression material. Plaster casts were made for assessment of the size, shape and location of tori. The size of tori was measured at the highest elevation of the outgrowth by another examiner (WA) using calipers (Model 505-666, Mitutoyo ( 0 , Japan) with output to the nearest 0.01 $\mathrm{mm}$. Each torus was measured three times on separate occasions with at least two weeks interval. The average size of tori was graded according to the classification of Reichart et al ${ }^{11}$ as follows: small ( $<3$ $\mathrm{mm})$, medium $(3-6 \mathrm{~mm})$ and large $(>6 \mathrm{~mm})$. The shapes of TP were classified as spindle, nodular, lobular and flat according to N eville et al. ${ }^{1}$ The locations of TP were classified as premolar, molar, premolar to molar, incisor to premolar, and incisor to molar areas.

TM was identified by number of nodes and their placements into four categories: bilateral single, bilateral multiple, unilateral single and unilateral multiple, as previously described by Kolas et al. ${ }^{6}$ Locations of TM were recorded as incisor, incisor to canine, incisor to premolar, incisor to molar, incisor $\&$ premolar, canine, canine to premolar, canine to molar, premolar, and premolar to molar areas.

The Statistical Package for Social Science (version 7.5) was used for the analyses. The Chi-square test was used to test for group differences. To evaluate patterns of predictor influence, especially sex and age, on the prevalence of both tori, the logistic regression model was employed. Differences between groups with $p \varangle 0.05$ were considered significant.

\section{REsULTS}

\section{Prevalence}

TP (Fig 1) and TM (Fig 2) were observed in $58.1 \%$ and $31.9 \%$ of the total subjects, respectively (Table 1). TP was found to be significantly higher

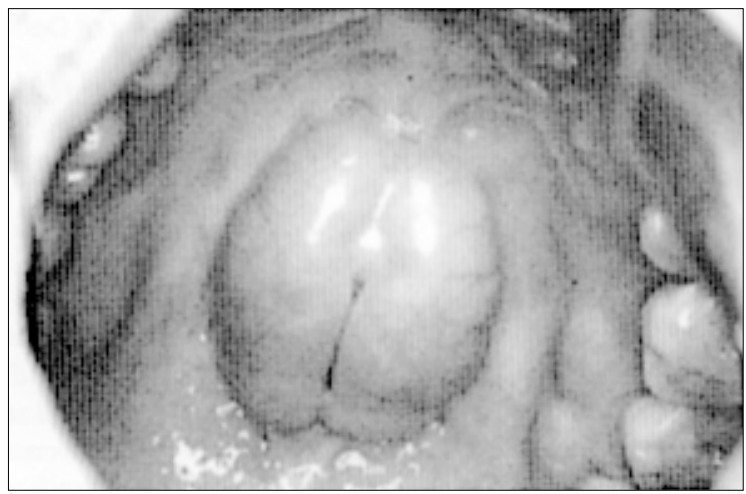

Fig 1. Lobular torus palatinus, a nodule of bone at the midline of hard palate in a Thai female, aged 48 years.

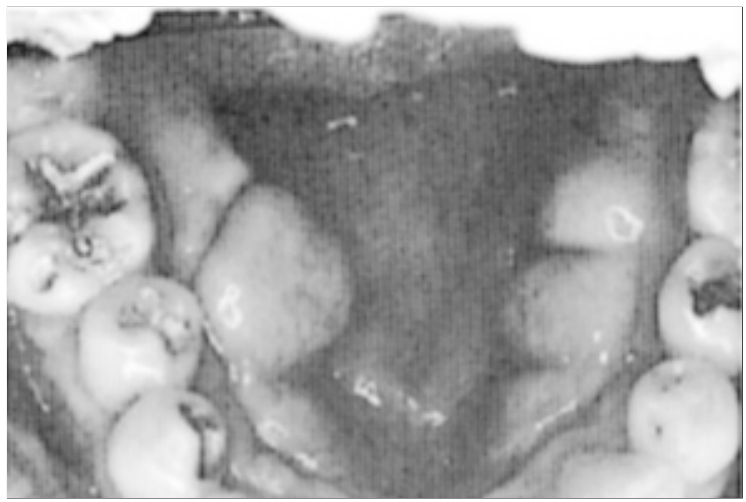

Fig 2. Bilateral multiple nodules of bony protuberance at the lingual aspect of mandible, the so-called torus mandibularis, in a Thai male, aged 53 years.

Table 1. Distribution of torus palatinus and torus mandibularis in relation to age and sex.

\begin{tabular}{ccccccccccc}
\hline $\begin{array}{c}\text { Age groups } \\
\text { (years) }\end{array}$ & $\mathbf{n}$ & $\mathbf{n}$ & $\begin{array}{c}\text { Males } \\
\mathbf{n}(\%)\end{array}$ & $\begin{array}{c}\text { Females } \\
\mathbf{n}(\%)\end{array}$ & $\mathbf{n}$ & $\begin{array}{c}\text { Males } \\
\mathbf{n}(\%)\end{array}$ & $\begin{array}{c}\text { Females } \\
\mathbf{n}(\%)\end{array}$ & $\mathbf{n}$ & $\begin{array}{c}\text { Total } \\
\mathbf{n}(\%)\end{array}$ & $\begin{array}{c}\text { Total } \\
\mathbf{n}(\%)\end{array}$ \\
\hline $13-19$ & 100 & $37(37.0)$ & $64(64.0)$ & 100 & $20(20.0)$ & $23(23.0)$ & 200 & $101(50.5)$ & $43(21.5)$ \\
$20-29$ & 100 & $39(39.0)$ & $60(60.0)$ & 100 & $29(29.0)$ & $30(30.0)$ & 200 & $99(49.5)$ & $59(29.5)$ \\
$30-39$ & 100 & $46(46.0)$ & $71(71.0)$ & 100 & $39(39.0)$ & $27(27.0)$ & 200 & $117(58.5)$ & $66(33.0)$ \\
$40-49$ & 100 & $61(61.0)$ & $68(68.0)$ & 100 & $39(39.0)$ & $27(27.0)$ & 200 & $129(64.5)$ & $66(33.0)$ \\
$50-59$ & 100 & $63(63.0)$ & $75(75.0)$ & 100 & $48(48.0)$ & $32(32.0)$ & 200 & $138(69.0)$ & $80(40.0)$ \\
$\geq 60$ & 100 & $47(47.0)$ & $66(66.0)$ & 100 & $34(34.0)$ & $35(35.0)$ & 200 & $113(56.5)$ & $69(34.5)$ \\
\hline Total & 600 & $293(48.8)$ & $404(67.3)$ & 600 & $209(34.8)$ & $174(29.0)$ & 1200 & $697(58.1)$ & $383(31.9)$ \\
\hline
\end{tabular}

Sex versus prevalence of $T P, X^{2}=42.172, d f=1, p<0.001$

Sex versus prevalence of $\mathrm{TM}, \mathrm{X}^{2}=4.698, \mathrm{df}=1, \mathrm{p}=0.030$

Age versus prevalence of $T P, X^{2}=24.168, d f=5, p<0.001$

Age versus prevalence of $T M, X^{2}=17.369, d f=5, p=0.004$ 
in females than in males $(67.3 \%$ versus $48.8 \%$; $\mathrm{p}<0.001$ ), while TM was found more often in males than in females ( $34.8 \%$ versus $29.0 \% ; p=0.030$ ) (Table 1). There was a significant correlation between the occurrence of both tori and age $(p<0.001$ for TP and $p=0.004$ for TM in Table 1 ). In addition, the prevalence of TP was higher in females than in males in all age groups, while the prevalence of TM was higher in males than in females in the 30-59 year age group (Table 1 ). To simultaneously evaluate patterns of predictor influence, especially sex and age on the prevalence of both tori, the logistic regression model was employed (Table 2 ). Females were 2.2 times as likely to have TP and 0.8 times as likely to have TM as males. The odd ratios of TP when compared with the 13-19 year age group increased from 1.8 times in the 40-49 year age group to 2.2 times in the 50-59 year age group and then decreased to 1.3 times in the $\geq 60$ year age group. The prevalence of TM when compared with the 1319 year age group increased from 1.8 times in the 30 39 year age group to 2.4 times in the $50-59$ year age group and decreased to 1.9 times in the older group.

\section{Size, Shape and Location of TP}

The relationship of TP occurrence and size to age and sex is shown in Table 3. Of the 697 TP studied, most werein small and medium sizes $(29.0 \%$ and $24.9 \%$, respectively). The age and sex differences in the distribution pattern of TP according to sizewere statistically significant ( $p \varangle 0.001$ ). The mean age of subjects having medium-sized TP $(41.2 \pm 15.3$ years $)$ was less than those having large-sized TP $(49.7+12.5$ years) ( $p<0.001$ ), but it was not different from those having small-sized TP $(39.9 \pm 17.9$ years). The medium- and large-sized TP tended to be found in females more than in males. The subjects in the older age group were more likely to have large-sized TP than those in the 13-19 year age group.

Table 4 shows the distribution of TP in relation to shape and size. Spindle-shaped TP was the most frequently observed, followed by the nodular TP. There was a relationship between shape and size of TP $(p<0.001)$. Most spindle-shaped TP were in medium and small sizes. Most nodular TP were of small size while most lobular TP were of medium size. All flat TP were small.

Table 2. Logistic regression model of torus pala tinus and torus ma ndibula ris.

\begin{tabular}{ccccc}
\hline \multirow{2}{*}{ Predictors } & \multicolumn{2}{c}{ TP } & & TM \\
\cline { 2 - 5 } & Odd ratio & p-value & Odd ratio & p-value \\
\hline Sex (1=Females) & 2.1963 & $\varangle 0.0001$ & 0.7611 & 0.0292 \\
Age 20-29 years & 0.9593 & 0.8384 & 1.5300 & 0.0669 \\
Age 30-39 years & 1.3991 & 0.1020 & 1.8022 & 0.0101 \\
Age 40-49 years & 1.8203 & 0.0041 & 1.8022 & 0.0101 \\
Age 50-59 years & 2.2455 & 0.0001 & 2.4425 & 0.0001 \\
Age $\geq 60$ years & 1.2852 & 0.2205 & 1.9278 & 0.0040 \\
\hline
\end{tabular}

Males and age 13-19 years were used as references.

Table 3. Distribution of torus palatinus in relation to age, sex and size

\begin{tabular}{|c|c|c|c|c|c|c|c|c|c|c|c|c|}
\hline \multirow{2}{*}{$\begin{array}{c}\text { Age } \\
\text { groups } \\
\text { (years) }\end{array}$} & \multicolumn{4}{|c|}{ Males } & \multicolumn{4}{|c|}{ Females } & \multicolumn{4}{|c|}{ Total } \\
\hline & $\mathbf{n}$ & $\begin{array}{l}\text { Small } \\
\text { n (\%) }\end{array}$ & $\begin{array}{c}\text { Medium } \\
\text { n (\%) }\end{array}$ & $\begin{array}{l}\text { Large } \\
\text { n (\%) }\end{array}$ & $n$ & $\begin{array}{l}\text { Small } \\
\text { n (\%) }\end{array}$ & $\begin{array}{c}\text { Medium } \\
\text { n (\%) }\end{array}$ & $\begin{array}{l}\text { Large } \\
\text { n (\%) }\end{array}$ & n & $\begin{array}{l}\text { Small } \\
\text { n (\%) }\end{array}$ & $\begin{array}{c}\text { Medium } \\
\text { n (\%) }\end{array}$ & $\begin{array}{l}\text { Large } \\
\text { n (\%) }\end{array}$ \\
\hline $13-19$ & 100 & $24(24.0)$ & $13(13.0)$ & $0(0.0)$ & 100 & $43(43.0)$ & $21(21.0)$ & $0(0.0)$ & 200 & 67 (33.5) & 34 (17.0) & $0(0.0)$ \\
\hline $20-29$ & 100 & $25(25.0)$ & $13(13.0)$ & $1(1.0)$ & 100 & $30(30.0)$ & $29(29.0)$ & $1(1.0)$ & 200 & 55 (27.5) & $42(21.0)$ & $2(1.0)$ \\
\hline $30-39$ & 100 & $23(23.0)$ & $21(21.0)$ & $2(2.0)$ & 100 & $22(22.0)$ & $43(43.0)$ & $6(6.0)$ & 200 & 45 (22.5) & $64(32.0)$ & $8(4.0)$ \\
\hline $40-49$ & 100 & $33(33.0)$ & $27(27.0)$ & $1(1.0)$ & 100 & $27(27.0)$ & $27(27.0)$ & $14(14.0)$ & 200 & $60(30.0)$ & $54(27.0)$ & $15(7.5)$ \\
\hline $50-59$ & 100 & $32(32.0)$ & $30(30.0)$ & $1(1.0)$ & 100 & $28(28.0)$ & $35(35.0)$ & $12(12.0)$ & 200 & $60(30.0)$ & 65 (32.5) & $13(6.5)$ \\
\hline$\geq 60$ & 100 & 31 (31.0) & $11(11.0)$ & $5(5.0)$ & 100 & $30(30.0)$ & $29(29.0)$ & $7(7.0)$ & 200 & $61(30.5)$ & $40(20.0)$ & $12(6.0)$ \\
\hline Total & 600 & $168(28.0)$ & 115 (19.1) & $10(1.7)$ & 600 & $180(30.0)$ & $184(30.7)$ & $40(6.6)$ & 1200 & $348(29.0)$ & 299 (24.9) & $50(4.2)$ \\
\hline
\end{tabular}

Age versus size, $X^{2}=36.212, d f=10, p<0.001$

Sex versus size, $X^{2}=17.093, d f=2, p \varangle 0.001$ 
Table 5 shows the distribution of TP in relation to age and location. The two most common locations for TP were the premolar to molar area and the molar area. Most TP in the 13-29 year age group were located in the molar area. There was an association between age and location of TP $(p<0.001)$. The number of TP located in the molar area when compared with the 13-19 year age group tended to decrease in the older age group. On the contrary, the number of TP located in the premolar to molar area when compared with the 13-29 year age group tended to increase with age.

\section{Size, Shape and Location of TM}

Table 6 shows the distribution of TM in relation to age, sex and size. Of the 383 TM studied, most TM were small. There was a statistical correlation between age of subjects in the distribution pattern

Table 4. Distribution of torus palatinus in relation to shape and size.

\begin{tabular}{lcccc}
\hline \multicolumn{1}{c}{ Shape } & \multicolumn{3}{c}{ Size } & Total \\
\cline { 2 - 4 } & $\begin{array}{c}\text { Small } \\
\mathbf{n}(\%)\end{array}$ & $\begin{array}{c}\text { Medium } \\
\mathbf{n}(\%)\end{array}$ & $\begin{array}{c}\text { Large } \\
\mathbf{n}(\%)\end{array}$ & $\begin{array}{c}\text { (n=697) } \\
\mathbf{n}(\%)\end{array}$ \\
\hline Spindle & $157(41.1)$ & $197(51.6)$ & $28(7.3)$ & $382(54.8)$ \\
Nodular & $157(64.6)$ & $77(31.7)$ & $9(3.7)$ & $243(34.9)$ \\
Lobular & $9(19.1)$ & $25(53.2)$ & $13(27.7)$ & $47(6.7)$ \\
Flat & $25(100.0)$ & $0(0.0)$ & $0(0.0)$ & $25(3.6)$ \\
\hline
\end{tabular}

Shape versus size, $X^{2}=97.009, d f=6, p<0.001$

Table 5. Distribution of torus palatinus in relation to age and location.

\begin{tabular}{ccccccc}
\hline $\begin{array}{c}\text { Age groups } \\
\text { (years) }\end{array}$ & $\mathbf{n}$ & \multicolumn{5}{c}{ Location } \\
\cline { 3 - 7 } & & $\begin{array}{c}\text { Premolararea } \\
\mathbf{n}(\%)\end{array}$ & $\begin{array}{c}\text { Molararea } \\
\mathbf{n}(\%)\end{array}$ & $\begin{array}{c}\text { Premolarto molararea } \\
\mathbf{n}(\%)\end{array}$ & $\begin{array}{c}\text { Others } \\
\mathbf{n}(\%)\end{array}$ & $\begin{array}{c}\text { Total } \\
\mathbf{n}(\%)\end{array}$ \\
\hline $13-19$ & 200 & $2(1.0)$ & $66(33.0)$ & $33(16.5)$ & $0(0.0)$ & $101(50.5)$ \\
$20-29$ & 200 & $4(2.0)$ & $59(29.5)$ & $36(18.0)$ & $0(0.0)$ & $99(49.5)$ \\
$30-39$ & 200 & $6(3.0)$ & $51(25.5)$ & $60(30.0)$ & $0(0.0)$ & $117(28.5)$ \\
$40-49$ & 200 & $11(5.5)$ & $47(23.5)$ & $71(35.5)$ & $0(0.0)$ & $129(64.5)$ \\
$50-59$ & 200 & $10(5.0)$ & $47(23.5)$ & $80(40.0)$ & $1(0.5)$ & $138(69.0)$ \\
$\geq 60$ & 200 & $12(6.0)$ & $47(23.5)$ & $53(26.5)$ & $1(0.5)$ & $113(56.5)$ \\
\hline Total & $\mathbf{1 2 0 0}$ & $\mathbf{4 5 ( 3 . 8 )}$ & $\mathbf{3 1 7 ( 2 6 . 4 )}$ & $\mathbf{3 3 3 ( 2 7 . 7 )}$ & $\mathbf{2 ( 0 . 2 )}$ & $\mathbf{6 9 7}(\mathbf{5 8 . 1})$ \\
\hline
\end{tabular}

Age versus location, $X^{2}=44.097, d f=15, p \varangle 0.001$

Table 6. Distribution of torus mandibula ris in relation to age, sex and size.

\begin{tabular}{|c|c|c|c|c|c|c|c|c|c|c|c|c|}
\hline \multirow{2}{*}{$\begin{array}{c}\text { Age } \\
\text { groups } \\
\text { (years) }\end{array}$} & \multicolumn{4}{|c|}{ Males } & \multicolumn{4}{|c|}{ Females } & \multicolumn{4}{|c|}{ Total } \\
\hline & $\mathbf{n}$ & $\begin{array}{l}\text { Small } \\
\text { n (\%) }\end{array}$ & $\begin{array}{c}\text { Medium } \\
\text { n (\%) }\end{array}$ & $\begin{array}{l}\text { Large } \\
\text { n (\%) }\end{array}$ & $\mathbf{n}$ & $\begin{array}{l}\text { Small } \\
\text { n (\%) }\end{array}$ & $\begin{array}{c}\text { Medium } \\
\text { n (\%) }\end{array}$ & $\begin{array}{l}\text { Large } \\
\text { n (\%) }\end{array}$ & n & $\begin{array}{l}\text { Small } \\
\text { n (\%) }\end{array}$ & $\begin{array}{c}\text { Medium } \\
\text { n (\%) }\end{array}$ & $\begin{array}{l}\text { Large } \\
\text { n (\%) }\end{array}$ \\
\hline $13-19$ & 100 & $14(14.0)$ & $6(6.0)$ & $0(0.0)$ & 100 & $19(19.0)$ & $4(4.0)$ & $0(0.0)$ & 200 & $33(16.5)$ & $10(5.0)$ & $0(0.0)$ \\
\hline $20-29$ & 100 & $21(21.0)$ & $8(8.0)$ & $0(0.0)$ & 100 & $24(24.0)$ & $6(6.0)$ & $0(0.0)$ & 200 & 45 (22.5) & $14(7.0)$ & $0(0.0)$ \\
\hline 30-39 & 100 & $24(24.0)$ & $12(12.0)$ & $3(3.0)$ & 100 & $13(13.0)$ & $13(13.0)$ & $1(1.0)$ & 200 & $37(17.5)$ & $25(12.5)$ & $4(2.0)$ \\
\hline 40-49 & 100 & $21(21.0)$ & $17(17.0)$ & $1(0.0)$ & 100 & $24(24.0)$ & $3(3.0)$ & $1(1.0)$ & 200 & $45(22.5)$ & $20(10.0)$ & $1(0.5)$ \\
\hline 50-59 & 100 & $24(24.0)$ & $18(18.0)$ & $6(6.0)$ & 100 & $23(23.0)$ & $8(8.0)$ & $1(1.0)$ & 200 & $47(23.5)$ & $26(13.0)$ & $7(3.5)$ \\
\hline$\geq 60$ & 100 & $21(21.0)$ & $9(9.0)$ & $4(4.0)$ & 100 & $16(16.0)$ & $16(16.0)$ & $3(3.0)$ & 200 & $37(18.5)$ & 25 (12.5) & $7(3.5)$ \\
\hline Total & 600 & $125(20.8)$ & 70 (11.7) & $14(2.3)$ & 600 & $119(19.8)$ & $50(8.3)$ & $5(0.8)$ & 1200 & $244(20.3)$ & $120(10)$ & 19 (1.6) \\
\hline
\end{tabular}

Age versus size, $X^{2}=21.159, d f=10, p=0.020$

Sex versus size, $X^{2}=4.584, d f=2, p=0.101$ 
of TM according to size ( $p=0.020$ ). The occurrence of TM in small, medium and large sizes was not significantly different between males and females $(p=0.101)$

The mean age of subjects having medium-sized TM $(44.0 \pm 15.8$ years) was less than those who exhibited large-sized TM (54.3 \pm 11.7 years) ( $p=0.007$ ), but it was not significantly different from that having small-sized TM (40.6 \pm 16.7 years).

The distribution of TM in relation to number of nodes and placements is shown in Table 7. Most TM were bilateral multiple (59.5\%), followed by the bilateral single (26.6\%), unilateral single $(11.0 \%)$ and unilateral multiple (2.9\%).

Bilateral TM was found in the symmetrical pattern (64.2\%) more than the asymmetrical pattern (35.8\%). When TM was unilateral (single and multiple), it occurred more often on the left side (9.4\%) than on the right side (5.5\%).

The most common location of TM was the canine to premolar area (40.5\%), followed by the premolar area $(25.7 \%)$, canine area $(13.8 \%)$, incisor to premolar area (7.0\%), canine to molar area $(6.8 \%)$, premolar to molar area $(2.8 \%)$ and incisor to canine area (1.4\%). The prevalence in other three locations was less than $1 \%$ each. No significant difference in location of TM was observed between right and left sides.

\section{Discussion}

The prevalence of TP and TM in this study corresponds with previous results in Mongoloids and other Asian populations. ${ }^{5,9-11,15,18}$ The high prevalence of tori in our study supports racial factor as one of the influences. Our results agree with most previous studies in showing that TP is more common in females, ${ }^{4-8,12,14-16}$ while TM is more common in males. ${ }^{3,11,12,15,16,19}$ The prevalence ratios of males to females for TP and TM in this study are also in accordance with other studies in Thais. ${ }^{11,15}$ Our study shows that females were 2.2 times as likely to have TP as males and 0.8 times as likely to have TM as males. Data from the present and previous reports

Table 7. Distribution of torus mandibula ris in relation to number of nodes and placements.

\begin{tabular}{lccc}
\hline Placements & \multicolumn{2}{c}{ Number of nodes } & Total \\
\cline { 2 - 3 } & $\begin{array}{c}\text { Multiple } \\
\mathbf{n}(\%)\end{array}$ & $\begin{array}{c}\text { Single } \\
\mathbf{n}(\%)\end{array}$ & $\begin{array}{c}\text { ( } \\
\text { ( }=383) \\
\mathbf{n}(\%)\end{array}$ \\
\hline Bilateral & $228(59.5)$ & $102(26.6)$ & $330(86.2)$ \\
Unilateral & $11(2.9)$ & $42(11.0)$ & $53(13.8)$ \\
\hline
\end{tabular}

in Thais suggest that the expression of tori is a sexrelated phenomenon. Haugen ${ }^{12}$ stated that there was no obvious explanation for the gender differences but suggested genetics as a responsible factor. Alvesalo et al ${ }^{24}$ studied TM in females with Turner syndrome $(45, X)$ and suggested that sexual dimorphism in the manifestation of TM might result from the effect of the $Y$ chromosome on the growth, occurrence, expression, and timing of development of TM. In the present study, the odd ratios of TP compared with the 13-19 year age group tended to increase with age from 40 to 59 year age group and those of TM tended to increase with age from 30 to 59 years. However, a trend for decreasing the occurrence of both tori was noted from the 50-59 year age group to the older age group. This variation in prevalence, therefore, should be influenced by functional factors. The regression of TP was probably observed after the extraction of teeth. ${ }^{22}$ Eggen \& $\mathrm{N}$ atvig ${ }^{19}$ reported the similar result in Norwegians and surmised that decreased prevalence of TM among persons over 50 years of age was related to the decrease in number of remaining teeth. Sonnier et $\mathrm{al}^{16}$ stated that the prevalence of TM was directly related to the presence of teeth. Our results show that functional influences may contribute to the clinical expression of TP and TM. Most of our subjects in the 60 years and over age group were partially edentulous or completely edentulous, hence decreased masticatory function was certain. The lower occurrence of tori may correlate with less occlusal stress. We also observed a correlation between the occurrence of tori and severe attrition of teeth in our subjects as did Reichart et al. ${ }^{11}$ The masticatory stress has been proposed as one of the etiologic factors. Eggen \& Natvig ${ }^{19}$ have also correlated the high prevalence of TM with increased masticatory stress. Recently, a strong association between clenching and grinding and the presence of TM has been reported in Thais. ${ }^{15}$

There are divergent observations on tori in regard to age. Muller \& M ayhall ${ }^{25}$ reported a continuously increasing prevalence of TM with age. King $\&$ $M$ oore $^{8}$ reported no great difference in the percentage of tori affected below the age of thirty and assumed that there was little or no further growth of tori after the age of thirty. Other investigators reported a peak of occurrence of tori in the third decade of life., 7 Our observations showed a peak of occurrence of both tori in the fifth decade. The present study included equal distribution of subjects in every age group while other studies had an excess of younger individuals but a shortage of older ones. This may 
explain why this study reported an older peak for occurrence of tori. We also found that subjects with older age were more likely to have medium- and large-sized TP than those with 13-19 year age group. In addition, the mean age of subjects with the large-sized tori was higher than those of mediumand small-sized tori. These findings support the association between age and continued growth of tori as reported by Topazian $\&$ Mullen. ${ }^{23}$

Small tori were found more frequently than large tori, as in previous reports. ${ }^{4,11-13}$ This finding contrasted with a study in Malaysia. ${ }^{9}$ Interestingly, our study showed that females had higher occurrence of TP and tended to have more medium- and largesized TP than males, while the results were demonstrated vice versa for TM. This observation is in accordance with the study in N orwegians. ${ }^{12}$ The large TP was found more common in older subjects as reported by $\mathrm{N}$ aidich et al. ${ }^{14}$

In a Singaporean study, Chew \& $\operatorname{Tan}^{10}$ reported that $37 \%$ of TP occupied two-thirds of the palate and concluded that the Chinese tended to have rather large tori. Most TP in our study were in the premolar to molar area. The prevalence of TP in the premolar to molar area tended to increase with age. This finding implies that this group of Thais al so tend to have rather large tori. In addition, during the first and the second decades of life, small-sized TP were found more frequently, but in the adult and older groups, the prevalence of medium- and large-sized TP increased. These findings indicate continued growth of TP in the forward direction from the molar area to the premolar area over time. The results supported the report of Gorsky et al ${ }^{13}$ that TP apparently grew with age from the molar area towards the premolar area.

In the present study, spindle-shaped TP was observed most frequently, followed by the nodular TP, as in Germans. ${ }^{11}$ Lobular TP was found with lesser frequency. Some authors have reported the lobular TP to be the rarest type. ${ }^{5,17}$ Kolas et al ${ }^{6}$ found the nodular TP to be the least frequent. The flat TP was the rarest type found in our study. This finding was in contrast with other studies in which this type of TP predominated. ${ }^{5-7,17}$

We observed more bilateral TM than unilateral TM and symmetrical occurrence predominated. These findings are in accordance with most studies. ${ }^{6}$, 11,12 In our study, TM was found to be in multiple nodules more than in single nodule which was in contrast with others that reported single tori as the most common type. 1, 6,11,12 We recorded unilateral TM more often on the left side of the mandible, whereas the right side unilateral TM predominated in other reports. ${ }^{11,14} \mathrm{We}$ also found that most TM were located at the canine to premolar area as in the previous reports. ${ }^{1}$

The high prevalence of both tori, as well as the differences in prevalence and size of tori with age and gender, support the hypothesis that torus should be considered a dynamic phenomenon, responding during life to environmental and functional factors, acting in a complicated interplay with the genetic factors. $^{12}$

\section{ACKNOMHgGements}

This study was supported by the grant from the Dental Research Fund, Faculty of Dentistry, Chulalongkorn University, Bangkok, Thailand. We are thankful to Assistance Professor Chanchai Hosanguan, Department of Community Dentistry, Faculty of Dentistry, Chulalongkorn University for his statistical advice; and Mrs Vanida Thongtha, Mrs Siriporn Payubtong and Miss M ayurage Prasomtong for their clinical assistance.

\section{Rererences}

1. Neville BW, Damm DD, Allen CM and Bouquot JE (1995) Oral and M axillofacial Pathology, pp 17-20. WB Saunders, Philadel phia.

2. Seah YH (1995) Torus palatinus and torus mandibularis: a review of the literature. Aust Dent J 40, 318-21.

3. Hrdlicka A (1940) Mandibular and maxillary hyperostoses. Am J Phys Anthropol 27, 1-67.

4. Miller SC and Roth H (1940) Torus palatinus: a statistical study. J Am Dent Assoc 27, 1950-7.

5. Woo JK (1950) Torus palatinus. Am J Phys Anthropol 8, 81-111.

6. Kolas S, Halperin V, Jefferis K, Huddleston $S$ and Robinson HBG (1953) The occurrence of torus palatinus and torus mandibularis in 2,478 dental patients. Oral Surg Oral Med Oral Pathol 6, 1134-41.

7. Austin JE, Radford GH and Banks SO JR (1965) Palatal and mandibular tori in the Negro. NY State Dent J 31, 187-91.

8. King DR and Moore GE (1971) The prevalence of torus palatinus. J Oral Med 26, 113-5.

9. Yaacob H, Tirmzi $\mathrm{H}$ and Ismail K (1983) The prevalence of oral tori in Malaysians. J Oral Med 38, 40-2.

10. Chew CL and Tan PH (1984) Torus palatinus. A clinical study. Aust Dent J 29, 245-8.

11. Reichart PA, N euhaus F and Sookasem M (1988) Prevalence of torus palatinus and torus mandibularis in Germans and Thai. Community Dent Oral Epidemiol 16,61-4.

12. Haugen LK (1992) Palatine and mandibular tori. A morphologic study in the current N orwegian population. Acta Odontol Scand 50, 65-77.

13. Gorsky M, Raviv M, Kfir E and M oskona D (1996) Prevalence of torus palatinus in a population of young and adult I sraelis. Arch Oral Biol 41, 623-5.

14. Naidich TP, ValenteM, Abrams K, Spreitzer JJ and Doundoulakis SH (1997) Torus palatinus. Int I N euroradiol 3, 229-43.

15. Kerdpon D and Sirirungrojying S (1999) A clinical study of oral tori in southern Thailand: prevalence and the relation to parafunctional activity. Eur J Oral Sci 107, 9-13. 
16. Sonnier KE, Horning GM and Cohen ME (1999) Palatal tubercles, palatal tori, and mandibular tori: prevalence and anatomical features in a U.S. population. J Periodontol 70, 329-36.

17. BernabaJM (1977) M orphology and incidence of torus palatinus and mandibularis in Brazilian Indians. J Dent Res 56, 499-501.

18. Moorrees CFA, Osborne RH and Wilde E (1952) Torus mandibularis. Its occurrence in Aleut children and its genetic determinants. Am J Phys Anthropol 10, 319-29.

19. Eggen S and Natvig B (1991) Variation in torus mandibularis prevalence in Norway. A statistical analysis using logistic regression. Community Dent Oral Epidemiol 19, 32-5.

20. Eggen S (1989) Torus mandibularis: an estimation of the degree of genetic determination. Acta Odontol Scand 47, 409-15.

21. Halffman CM, Scott GR and Pedersen PO (1992) Palatinetorus in the Greenlandic Norse. Am J Phys Anthropol 88, 145-61.

22. Johnson OM (1959) The tori and masticatory stress. J Prosthet Dent 9, 975-7.

23. Topazian DS and Mullen FR (1977) Continued growth of a torus palatinus. J Oral Surg 35, 845-6.

24. Alvesalo L, Mayhall JT and VarrelaJ (1996) Torus mandibularis in 45,X females (Turner syndrome). Am J Phys Anthropol 101, $145-9$.

25. Muller TP and Mayhall JT (1971) Analysis of contingency table data on torus mandibularis using a log linear model. Am J Phys Anthropol 34, 149-53. 